\title{
Comprehensive knowledge about HIV/ AIDS and associated factors among women of reproductive age in sub-Saharan Africa: a multilevel analysis using the most recent demographic and health survey of each country
}

Achamyeleh Birhanu Teshale ${ }^{1 *}$, Yigizie Yeshaw ${ }^{1,2}$, Adugnaw Zeleke Alem¹, Hiwotie Getaneh Ayalew ${ }^{3}$, Alemneh Mekuriaw Liyew ${ }^{1}$, Zemenu Tadesse Tessema', Getayeneh Antehunegn Tesema', Misganaw Gebrie Worku ${ }^{4}$ and Tesfa Sewunet Alamneh ${ }^{1}$

\begin{abstract}
Background: Women of reproductive age in sub-Saharan African (SSA) share the greatest burden of the HIV/AIDS epidemic. Comprehensive knowledge about HIV is seen as pivotal in combating the epidemic. Therefore, this study aimed to assess comprehensive knowledge about HIV/AIDS and associated factors among women of reproductive age in sub-Saharan Africa.
\end{abstract}

Objective: To examine comprehensive knowledge about HIV/AIDS and associated factors among women of reproductive age in sub-Saharan Africa.

Methods: We used the most recent SSA countries Demographic and Health Surveys (DHS) data. To assess comprehensive knowledge, a composite score of six separate questions (can get HIV by witchcraft or supernatural means, can reduce risk of getting HIV by using condoms during sex, reduce the risk of getting HIV by having one sex partner only, can get HIV from mosquito bites, can get HIV by sharing food with a person who has HIV/AIDS, and a healthy-looking person can have HIV) was used. Those who answered all six questions correctly were considered to have comprehensive knowledge. To assess the factors associated with comprehensive knowledge of HIV/AIDS, we used a multilevel binary logistic regression model since the data had hierarchical nature.

Results: In this study, the comprehensive knowledge about HIV/AIDS was 38.56\% (95\% Cl: 38.32, 38.75). Both individual and community-level factors were associated with comprehensive knowledge about HIV/AIDS. Among individuallevel factors, older age, having primary and above educational level, being from wealthy households, contraceptive use, listening to the radio, and reading newspaper were associated with higher odds of comprehensive knowledge about HIV/AIDS. Being from urban areas and the Eastern African region were the community-level factors that were associated with higher odds of comprehensive knowledge about HIV/AIDS.

\footnotetext{
*Correspondence: achambir08@gmail.com

${ }^{1}$ Department of Epidemiology and Biostatistics, Institute of Public Health,

College of Medicine and Health Sciences, University of Gondar, Gondar,

Ethiopia

Full list of author information is available at the end of the article
}

(c) The Author(s) 2022. Open Access This article is licensed under a Creative Commons Attribution 4.0 International License, which permits use, sharing, adaptation, distribution and reproduction in any medium or format, as long as you give appropriate credit to the original author(s) and the source, provide a link to the Creative Commons licence, and indicate if changes were made. The images or other third party material in this article are included in the article's Creative Commons licence, unless indicated otherwise in a credit line to the material. If material is not included in the article's Creative Commons licence and your intended use is not permitted by statutory regulation or exceeds the permitted use, you will need to obtain permission directly from the copyright holder. To view a copy of this licence, visit http://creativecommons.org/licenses/by/4.0/. The Creative Commons Public Domain Dedication waiver (http://creativecommons.org/publicdomain/zero/1.0/) applies to the data made available in this article, unless otherwise stated in a credit line to the data. 
Conclusion: The study found that comprehensive knowledge of HIV/AIDS is low. Individual and community-level factors were associated with comprehensive knowledge of HIV/AIDS. Therefore, giving special attention to those young women, women who had no formal education, those from poor socioeconomic status, and those who are from remote areas could decrease the epidemics of HIV/AIDS by increasing the comprehensive knowledge about HIV/AIDS. Besides, it is better to strengthen media campaigns regarding HIV/AIDS to increase comprehensive knowledge about HIV/AIDS.

Keywords: Comprehensive knowledge, HIV/AIDS, Sub-Saharan Africa

\section{Background}

The human immunodeficiency virus (HIV) is a global public health problem that takes the lives of about 33 million people. By the end of 2019, an estimated 38.0 million individuals were living with HIV, with 1.7 million new infections and 690,000 HIV-related deaths [1]. The vast majority of HIV-positive people are living in low- and middle-income countries, with the majority (68\%) in subSaharan Africa (SSA) [2, 3]. Furthermore, in SSA, women of reproductive age are at greater risks of the pandemic [4].

The objectives of the 2030 Sustainable Development Goal 3 is attaining good health and well-being for all [5, 6]. However, the HIV/AIDS pandemic is a potential challenge to the achievement of these goals and remains the greatest cause of morbidity and mortality in low and middle-income countries [7-9].

Currently, the new HIV infection rate is high and different factors are associated with the risk of acquiring HIV infections. According to different studies conducted elsewhere, factors such as educational status, age, wealth status, media exposure, drug use, and consumption of alcohol are associated with acquiring HIV infections [10-13].

The other potential explanation for the occurrence of a higher new infection is due to low comprehensive knowledge about HIV/AIDS. Different scholars revealed that comprehensive knowledge about HIV is seen as pivotal in combating the epidemic [14-16]. Globally, women of reproductive age are at risk of acquiring HIV infection and only $30 \%$ of them have comprehensive knowledge about HIV/AIDS [4]. According to different scholars, the prevalence of comprehensive knowledge in Africa, particularly in sub-Saharan Africa is low, which ranges from 19.3\% in Ethiopia to 48.9\% in Burundi $[14,17,18]$. Different factors such as education, wealth status, place of residence, sex of household head, region, and media exposure are associated with comprehensive knowledge about HIV/AIDS [14, 19-21].

While there has been a progress towards the United Nations program on HIV/AIDS' 90-90-90 targets for prevention and treatment, the targets are not achieved by 2020 [3]. Besides, low comprehensive knowledge about HIV/AIDS is reported in different SSA countries and evidence regarding the factors associated with comprehensive knowledge about HIV remains scanty. Moreover, up to our knowledge, there was no study on comprehensive knowledge about HIV/AIDS by pooling data of sub-Saharan Africa countries. Therefore, we aimed to investigate comprehensive knowledge about HIV/AIDS among women of reproductive age and its associated factors in sub-Saharan Africa. This helps policymakers to prevent the epidemics of HIV/AIDS through increasing awareness about HIV/AIDS by giving priority to the identified vulnerable groups.

\section{Methods}

\section{Data source}

We have used the most recent SSA countries Demographic and Health Surveys (DHS) data. For each countries DHS, the most recent Population and Housing Census was used as a sampling frame. The DHS sample was stratified and selected in two stages and the survey target groups were women and men of reproductive age in randomly selected households of each country. Then, detailed information was collected on background characteristics, maternal and child health, HIV/AIDS, domestic violence, and other important public health problems. Five questionnaires were used to collect the DHS data: the household questionnaire, the woman's questionnaire, the man's questionnaire, the biomarker questionnaire, and the health facility questionnaire. The data collection tool was pretested and extensive training was given for the data collectors. Further information about DHS data collection technique, in general, the DHS methodology can be found in each countries survey report.

For this study, we used the most recent DHS data that was conducted from 2015 to 2020 . There were 19 countries with DHS conducted in the study period. However, we appended 15 countries' DHS data for our analysis since the four countries (Senegal, South Africa, Tanzania, and Angola) DHS had no observation regarding comprehensive knowledge towards HIV/AIDS (Table 1). 
Table 1 Overall sample size and sample per each countries DHS and survey year

\begin{tabular}{lllr}
\hline Country and region & Year & $\begin{array}{l}\text { Total } \\
\text { population } \\
\text { (N=202,270) }\end{array}$ & Percentage (\%) \\
\hline Eastern African region & & 86,188 & 41.61 \\
Burundi & $2016 / 17$ & 16,468 & 8.14 \\
Ethiopia & 2016 & 14,599 & 7.22 \\
Rwanda & 2015 & 13,428 & 6.64 \\
Uganda & 2016 & 18,435 & 9.11 \\
Zambia & $2018 / 19$ & 13,394 & 6.62 \\
Zimbabwe & 2015 & 9864 & 4.88 \\
Western African region & & 98,076 & 48.49 \\
Benin & $2017 / 18$ & 7053 & 3.49 \\
Gambia & $2019 / 20$ & 11,575 & 5.72 \\
Guinea & 2018 & 8811 & 4.36 \\
Liberia & $2019 / 20$ & 7622 & 2.89 \\
Mali & 2018 & 8979 & 4.44 \\
Nigeria & 2018 & 39,433 & 19.50 \\
Sierra Leone & 2019 & 14,603 & 7.22 \\
Central African region & & 18,006 & 8.90 \\
Cameroon & $2018 / 19$ & 13,250 & 6.55 \\
Chad & 2015 & 4756 & 2.35 \\
\hline
\end{tabular}

\section{Variables of the study \\ Outcome variable}

The outcome variable in this study was comprehensive knowledge about HIV/AIDS. It was a composite score of six different questions: 1. Can get HIV by witchcraft or supernatural means, 2. Can reduce risk of getting through using condoms during sex, 3. Reduce the risk of getting HIV by having one sex partner only, 4. Can get HIV from mosquito bites, 5. Can get HIV by sharing food with a person who has HIV/AIDS, and 6. A healthy-looking person can have HIV $[19,22,23]$.

Then a woman had correct comprehensive knowledge if she answers all the six questions correctly (said "No" for questions 1, 4, and 5 and said "Yes" for other questions) and not knowledgeable if she did not give the correct answer for at least one of the questions.

\section{Independent variables}

After searching literature [19-21, 23, 24], we have incorporated both individual and community level independent variables.

Individual-level variables maternal age, marital status, educational level, wealth status, sex of household head, contraceptive usage, reading a newspaper, listening to the radio, and watching television were the individual-level variables. Maternal age was categorized as $15-19,20-24,25-29,30-34,35-39,40-44$, and 45-49 years while marital status was categorized as single, married, widowed, and divorced/separated. The other variables were categorized as follows: educational level (no formal education, primary education, secondary education, higher education), wealth status (poorest, poorer, middle, richer, richest), sex of household head (male, female), contraceptive usage (yes, no), reading a newspaper (yes, no), listening to the radio (yes, no), and watching television (yes, no).

Community-level variables Place of residence and African region were incorporated as community-level variables. The place of residence was categorized as urban and rural. According to different literatures, African regions are categorized as Eastern, Western, Central, and Southern regions [25]. However, for our study, we did not have countries in the southern African region that have data on the outcome variable and, therefore, African regions were categorized as Eastern, Western, and Central African regions.

\section{Data management and statistical analysis}

We used Stata version 14.0 software to extract, recode, and conduct the overall analysis. Throughout the analysis, we have applied weighting to restore the representativeness and to get a better statistical estimate (robust standard error) [26]. Due to the nature of the DHS data, we have done a multilevel analysis. Four multilevel models were fitted. The first model (model I) was fitted with only the outcome variable to assess the variability of the comprehensive knowledge about HIV/AIDS between clusters or to assess the intra-class correlation coefficient (ICC). The second model (model 2) was fitted using individual-level variables only. Model III was fitted with community-level variables only and model IV was fitted with both individual and community-level variables.

To assess the community level variability of comprehensive knowledge about HIV/AIDS (for random effect analysis), ICC, Median Odds Ratio (MOR), and proportional change in variance $(\mathrm{PCV})$ were calculated. To verify model fitness, deviance was used and the bestfit model has been deemed a model with the lowest deviance.

Moreover, eligible variables for the multivariable analysis were selected using a bivariable analysis, and variables with a p-value $<0.20$ in the bivariable analysis were qualified for the multivariable analysis. In the multivariable analysis, the adjusted odds ratio (AOR) with its 95\% confidence interval (CI) was reported, and variables with a p-value $<0.05$ were considered as significant predictors of comprehensive knowledge about HIV/AIDS. 


\section{Results}

\section{Sociodemographic characteristics of respondents}

We used a total weighted sample of 202,270 women of reproductive age for this study. The majority (21.11\%) of the respondents were in the age group 15-19 years. Most, $74.15 \%$, of the respondents were from maleheaded households and around $63.36 \%$ of the respondents were married. Regarding reading a newspaper and listening to the radio, about $16.92 \%$ and $57.39 \%$ of study participants read the newspaper and listens to the radio respectively. Moreover, the majority, $60.25 \%$ and $48.49 \%$ of study participants were from rural areas and the West African region respectively (Table 2).

\section{Comprehensive knowledge about HIV/AIDS in sub-Saharan Africa}

The comprehensive knowledge of HIV/AIDS was $38.54 \%$ (95\% CI: 38.32, 38.75). The majority of the study participants had higher knowledge regarding each of the individual knowledge-related questions (Table 3). As illustrated in Fig. 1, there were wide differences in comprehensive knowledge about HIV/AIDS between individual countries, ranging from 10.3\% (95\% CI: 9.6, $11.03)$ in Benin to $66.38 \%$ (95\% CI: $65.58,67.17)$ in Rwanda (Fig. 1).

Moreover, as shown in Fig. 2, the comprehensive knowledge about HIV/AIDS was highest in the Eastern African region, which was 47.53\% (95\% CI: 47.20, 47.87) (Fig. 2).

\section{Factors associated with comprehensive knowledge about HIV/AIDS among women of reproductive age in sub-Saharan Africa \\ Random effect analysis}

As we have seen from Table 4, all of the parameters favor the final model as the best model. The ICC in the model I indicates that about $10 \%$ of the variability in comprehensive knowledge about HIV/AIDS was attributed to the community/cluster level variability. The MOR in the model I also revealed that if we took two women from two different clusters (one from a cluster with higher comprehensive knowledge and one from a cluster with lower comprehensive knowledge) the odds of having comprehensive knowledge about HIV/AIDS among women who come from clusters with higher comprehensive knowledge was 1.78 times higher as compared to their counterparts. Moreover, the PCV in the final model (model IV) showed that about 24\% of the variability in comprehensive knowledge was explained by both community-level and individuallevel factors. Regarding model fitness, model IV was the best-fitted model since it had the lowest deviance
Table 2 Sociodemographic characteristics of respondents

\begin{tabular}{|c|c|c|}
\hline Characteristics & $\begin{array}{l}\text { Weighted frequency } \\
(\mathrm{N}=202,270)\end{array}$ & Percentage (\%) \\
\hline \multicolumn{3}{|l|}{ Age } \\
\hline $15-19$ & 42,696 & 21.11 \\
\hline $20-24$ & 36,617 & 18.10 \\
\hline $25-29$ & 35,781 & 17.69 \\
\hline $30-34$ & 29,320 & 14.50 \\
\hline $35-39$ & 25,055 & 12.39 \\
\hline $40-44$ & 18,085 & 8.94 \\
\hline $45-49$ & 14,716 & 7.28 \\
\hline \multicolumn{3}{|l|}{ Educational level } \\
\hline No formal education & 63,081 & 31.19 \\
\hline Primary education & 58,924 & 29.13 \\
\hline Secondary education & 67,403 & 33.32 \\
\hline Higher education & 12,862 & 6.36 \\
\hline \multicolumn{3}{|l|}{ Wealth status } \\
\hline Poorest & 34,095 & 16.86 \\
\hline Poorer & 36,947 & 18.27 \\
\hline Middle & 38,426 & 19.00 \\
\hline Richer & 43,227 & 21.37 \\
\hline Richest & 49,575 & 24.51 \\
\hline \multicolumn{3}{|l|}{ Sex of household head } \\
\hline Male & 149,979 & 74.15 \\
\hline Female & 52,291 & 25.85 \\
\hline \multicolumn{3}{|l|}{ Contraceptive use } \\
\hline Yes & 46,196 & 22.84 \\
\hline No & 156,074 & 77.16 \\
\hline \multicolumn{3}{|l|}{ Marital status } \\
\hline Never in union & 57,645 & 28.50 \\
\hline Married & 128,166 & 63.36 \\
\hline Widowed & 5488 & 2.71 \\
\hline Divorced/separated & 10,971 & 5.42 \\
\hline \multicolumn{3}{|l|}{ Reading newspaper } \\
\hline No & 168,036 & 83.08 \\
\hline Yes & 34,234 & 16.92 \\
\hline \multicolumn{3}{|l|}{ Listening radio } \\
\hline No & 86,180 & 42.61 \\
\hline Yes & 116,090 & 57.39 \\
\hline \multicolumn{3}{|l|}{ Watching television } \\
\hline No & 114,050 & 56.38 \\
\hline Yes & 88,220 & 43.62 \\
\hline \multicolumn{3}{|l|}{ Place of residence } \\
\hline Urban & 80,397 & 39.75 \\
\hline Rural & 121,873 & 60.25 \\
\hline \multicolumn{3}{|l|}{ African region } \\
\hline Eastern African region & 86,188 & 41.61 \\
\hline Western African region & 98,076 & 48.49 \\
\hline Central African region & 18,006 & 8.90 \\
\hline
\end{tabular}


Table 3 Comprehensive knowledge of HIV/AIDS in sub-Saharan Africa

\begin{tabular}{|c|c|c|}
\hline Variables & Frequency & Percentage (\%) \\
\hline \multicolumn{3}{|c|}{ 1. Can get HIV by witchcraft or supernatural means } \\
\hline Yes & 38,755 & 19.16 \\
\hline No & 163,515 & 80.84 \\
\hline \multicolumn{3}{|c|}{ 2. Reduce the risk of getting HIV: always use condoms during sex } \\
\hline No & 44,381 & 21.94 \\
\hline Yes & 157,889 & 78.06 \\
\hline \multicolumn{3}{|c|}{ 3. Reduce the risk of getting HIV: have 1 sex partner only } \\
\hline No & 23,894 & 11.81 \\
\hline Yes & 178,376 & 88.19 \\
\hline \multicolumn{3}{|c|}{ 4. Can get HIV from mosquito bites } \\
\hline Yes & 61,387 & 30.35 \\
\hline No & 140,883 & 69.65 \\
\hline \multicolumn{3}{|c|}{ 5. Can get HIV by sharing food with a person who has AIDS } \\
\hline Yes & 45,805 & 22.65 \\
\hline No & 156,465 & 77.35 \\
\hline \multicolumn{3}{|c|}{ 6. A healthy-looking person can have HIV } \\
\hline No & 41,279 & 20.41 \\
\hline Yes & 160,991 & 79.59 \\
\hline \multicolumn{3}{|c|}{ 7. Comprehensive knowledge } \\
\hline No & 124,323 & 61.46 \\
\hline Yes & 77,947 & 38.56 \\
\hline
\end{tabular}

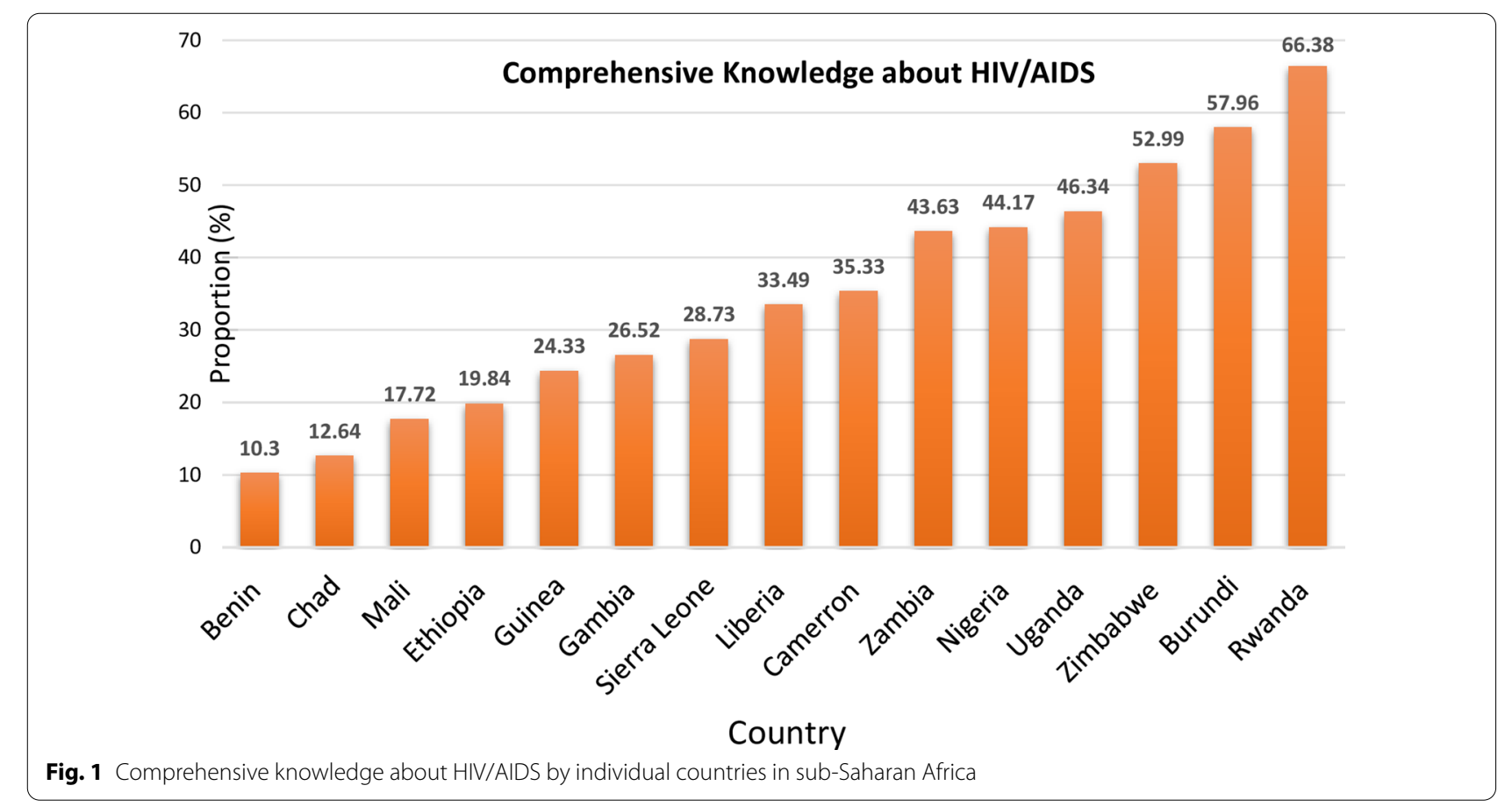

and we used this model while assessing the factors associated with comprehensive knowledge about HIV/ AIDS (Table 4).

\section{Fixed effects analysis}

All variables in the bivariable analysis were eligible for the multivariable analysis. In the multivariable multilevel 


\section{Comprehnsive knowledge about HIV/AIDS}

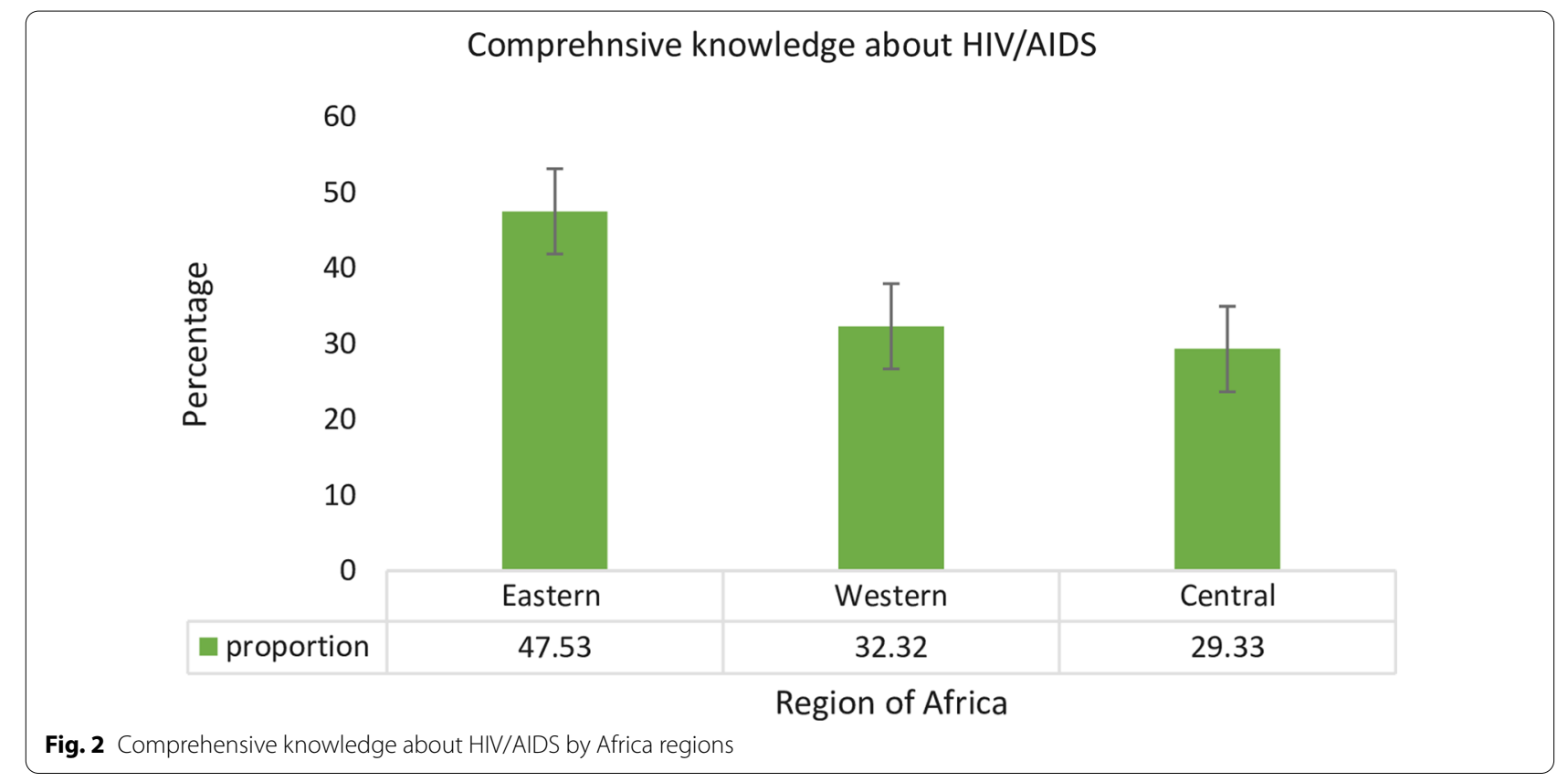

Table 4 Random effect analysis for factors associated with comprehensive knowledge of HIV/AIDS among women of reproductive age in sub-Saharan Africa

\begin{tabular}{llcrr}
\hline Parameter & Model I & Model II & Model II & Model IV \\
\hline Community-level variance & 0.367 & 0.333 & 0.299 & 0.278 \\
ICC & 0.10 & 0.09 & 0.08 & 0.07 \\
MOR & 1.78 & 1.73 & 1.68 & 1.65 \\
PCV & Reference & 0.09 & 0.19 & 0.24 \\
Log-likelihood & $-132,811.61$ & $-126,497.01$ & $-128,170.14$ & $-124,139.5$ \\
Deviance & $265,623.22$ & $252,994.02$ & $256,340.28$ & 248,279 \\
\hline
\end{tabular}

analysis.

In the multivariable analysis, the odds of having comprehensive knowledge about HIV/AIDS was higher among older age groups as compared with those whose age was between 15 and 19 years. Being having a formal education, secondary education, and higher education, respectively, was associated with 1.37 (AOR: 1.37; 95\% CI: 1.32, 1.44), 2.19 (AOR: 2.19; 95\% CI: 2.08, 2.30), and 3.67 (AOR: 3.67; 95\% CI: 3.42, 3.94) times higher odds of comprehensive knowledge as compared to those who had no formal education. Women who were from the middle, richer, and richest households had 1.14 (AOR: 1.14; 95\% CI: 1.07, 1.20), 1.16 (AOR: 1.16; 95\% CI: 1.09, 1.23), and 1.28 (AOR: 1.28 ; 95\% CI: 1.19, 1.37) times higher odds of comprehensive knowledge, respectively, as compared to those who came from poorest households. Being using contraceptive methods was associated with 1.09 (AOR: 1.09; 95\% CI: $1.05,1.13$ ) times higher odds of comprehensive knowledge as compared to their counterparts.
Regarding reading newspaper, women who read the newspaper had 1.18 (AOR: 1.18; 95\% CI: 1.13, 1.22) times higher odds of comprehensive knowledge compared to their counterparts. The odds of having comprehensive knowledge about HIV/AIDS was 20\% (AOR: 0.80; 95\% CI: $0.77,0.82)$ lower among women who did not listen to the radio as compared with their counterparts. Being from the urban area had 1.10 (AOR: 1.10; 95\% CI: 1.03, 1.18) times higher odds of comprehensive knowledge compared to their counterparts. Regarding the African region, women from the Eastern African region had 2.22 (AOR: 2.22; 95\% CI: 2.09, 2.35) times higher odds of comprehensive knowledge about HIV/AIDS as compared to women from the Western African region (Table 5).

\section{Discussion}

This study found that the comprehensive knowledge about HIV/AIDS among women of reproductive age was $38.54 \%$. Besides, there was a huge differences in 
Table 5 Multilevel analysis of factors associated with comprehensive knowledge of HIV/AIDS among women of reproductive age in SSA

\begin{tabular}{|c|c|c|c|c|}
\hline Variables & Model I & Model II AOR (95\% CI) & Model III AOR (95\% CI) & Model IV AOR $(95 \% \mathrm{Cl})$ \\
\hline \multicolumn{5}{|l|}{ Age } \\
\hline $15-19$ & & 1.00 & & 1.00 \\
\hline $20-24$ & & $1.34(1.29,1.40)$ & & $1.33(1.28,1.38)^{* * *}$ \\
\hline $25-29$ & & $1.47(1.40,1.53)$ & & $1.46(1.40,1.53)^{* * *}$ \\
\hline $30-34$ & & $1.66(1.58,1.75)$ & & $1.63(1.55,1.72)^{* * *}$ \\
\hline $35-39$ & & $1.61(1.52,1.69)$ & & $1.60(1.52,1.69)^{* * *}$ \\
\hline $40-44$ & & $1.59(1.50,1.68)$ & & $1.56(1.48,1.65)^{* * *}$ \\
\hline $45-49$ & & $1.58(1.49,1.68)$ & & $1.58(1.48,1.68)^{* * *}$ \\
\hline \multicolumn{5}{|l|}{ Educational level } \\
\hline No formal education & & 1.00 & & 1.00 \\
\hline Primary education & & $1.79(1.72,1.87)$ & & $1.37(1.32,1.44)^{* * * *}$ \\
\hline Secondary education & & $2.37(2.26,2.49)$ & & $2.19(2.08,2.30)^{* * *}$ \\
\hline Higher education & & $3.78(3.53,4.06)$ & & $3.67(3.42,3.94)^{* * *}$ \\
\hline \multicolumn{5}{|l|}{ Wealth status } \\
\hline Poorest & & 1.00 & & 1.00 \\
\hline Poorer & & $1.03(0.98,1.08)$ & & $1.05(0.99,1.10)$ \\
\hline Middle & & $1.13(1.07,1.19)$ & & $1.14(1.07,1.20)^{* * *}$ \\
\hline Richer & & $1.21(1.14,1.28)$ & & $1.16(1.09,1.23)^{* * *}$ \\
\hline Richest & & $1.44(1.35,1.54)$ & & $1.28(1.19,1.37)^{* * *}$ \\
\hline \multicolumn{5}{|l|}{ Sex of household head } \\
\hline Male & & 1.00 & & 1.00 \\
\hline Female & & $1.03(0.99,1.06)$ & & $0.99(0.95,1.02)$ \\
\hline \multicolumn{5}{|l|}{ Contraceptive use } \\
\hline Yes & & $1.22(1.18,1.26)$ & & $1.09(1.05,1.13)^{* * *}$ \\
\hline No & & 1.00 & & 1.00 \\
\hline \multicolumn{5}{|l|}{ Marital status } \\
\hline Never in union & & $1.09(1.04,1.14)$ & & $1.04(0.99,1.09)$ \\
\hline Married & & 1.00 & & 1.00 \\
\hline Widowed & & $1.17(1.09,1.27)$ & & $1.08(0.99,1.17)$ \\
\hline Divorced/Separated & & $1.09(1.03,1.16)$ & & $0.98(0.93,1.04)$ \\
\hline \multicolumn{5}{|l|}{ Reading newspaper } \\
\hline No & & 1.00 & & 1.00 \\
\hline Yes & & $1.32(1.27,1.38)$ & & $1.18(1.13,1.22)^{* * *}$ \\
\hline \multicolumn{5}{|l|}{ Listening radio } \\
\hline No & & $0.77(0.74,0.79)$ & & $0.80(0.77,0.82)^{* * *}$ \\
\hline Yes & & 1.00 & & 1.00 \\
\hline \multicolumn{5}{|l|}{ Watching television } \\
\hline No & & 1.00 & & 1.00 \\
\hline Yes & & $0.80(0.77,0.84)$ & & $0.96(0.92,1.01)$ \\
\hline \multicolumn{5}{|l|}{ Place of residence } \\
\hline Urban & & & $2.51(2.07,3.04)$ & $1.10(1.03,1.18)^{* *}$ \\
\hline Rural & & & 1.00 & 1.00 \\
\hline \multicolumn{5}{|l|}{ African region } \\
\hline Eastern African region & & & $4.49(3.61,5.59)$ & $2.22(2.09,2.35)^{* * *}$ \\
\hline Western African region & & & 1.00 & 1.00 \\
\hline Central African region & & & $0.85(0.69,1.05)$ & $0.98(0.89,1.09)$ \\
\hline
\end{tabular}

***p value $<0.001, * * p$ value $<0.01$ 
comprehensive knowledge about HIV/AIDS between individual SSA countries, from $10.3 \%$ in Benin to $66.38 \%$ in Rwanda.

The proportion of comprehensive knowledge about HIV/AIDS found in this study, is consistent with a study conducted in Uganda [18] and lower than a study finding from Burundi, Kenya, and Uganda [14]. Besides, this figure is higher than findings from northern Uganda and Ethiopia [14, 27]. The variation found in this study (between SSA countries) and the variation with other previous studies may be due to the difference in socioeconomic and socio-cultural characteristics of respondents between countries. In addition, this study is based on pooled analysis that incorporates data of the subSaharan African countries; others incorporate data of a single country.

In this study, different factors were associated with comprehensive knowledge about HIV/AIDS. The odds of having comprehensive knowledge about HIV/AIDS was higher among older women as compared to younger-aged women. This is in line with studies conducted in Bangladesh and Uganda $[18,28]$. This may be because the traditional social system and health care service often bother older age group women. Besides, younger age women had a barrier to communicate with adults regarding sexrelated information and sexually transmitted diseases.

Educational status had significantly associated with comprehensive knowledge about HIV/AIDS. Women with primary and higher educational status had higher odds of having comprehensive knowledge about HIV/ AIDS compared to those mothers with no formal education. This finding is congruent with studies done in Ethiopia [19, 29], Bangladesh [24, 30], and Vietnam [31]. This may be since educated women can attain more knowledge when they are exposed to different information sources such as printed paper and radio. The other plausible explanation is education causes women to be more positive about their health and to look for information to protect themselves against HIV/AIDS. Moreover, educated women are more likely to get information regarding HIV from school-based HIV/AIDS interventions.

The study at hand revealed that mothers from the middle, richer, and richest households had higher odds of comprehensive knowledge about HIV/AIDS as compared to those who were from the poorest households. This is in agreement with studies conducted elsewhere $[14,18$, $20,21]$. The possible explanation is having good socioeconomic status helps to accesses different media and increases educational achievement, which increases the likelihood of knowledge about HIV/AIDS [32].

Consistent with other studies conducted elsewhere $[18,19,24,28,29]$, in this study, being having exposure to radio and newspaper was associated with higher odds of comprehensive knowledge about HIV/AIDS as compared to their counterparts. This might be since media has a huge influence in educating and conveying proper knowledge that reduces pre-existing misunderstandings regarding HIV/AIDS.

The study also identified women from urban areas had higher odds of comprehensive knowledge about HIV/ AIDS as compared to women from rural areas. This is consistent with a study conducted elsewhere [18, 20, 28]. The possible reason could be rural women are often with the great problem in terms of access to health-related information, schooling, media, and healthcare facilities. Besides, those women who reside in rural areas also had less exposure to HIV/AIDS-related information such as HIV testing and counseling campaigns and different training sessions that increase awareness about HIV/ AIDS.

Moreover, there were regional variations regarding comprehensive knowledge about HIV/AIDS in which women from the Eastern African region had higher odds of comprehensive knowledge about HIV/AIDS compared to those from the Western African region. This regional variation is supported by studies conducted in Bangladesh [28] and Ghana [20]. This could be due to the difference in terms of access to education, media, and sociocultural and socioeconomic status between regions.

This study had both strengths and limitations. It was based on a relatively large dataset. It was also based on an appropriate model (multilevel modeling) to account for the hierarchical nature of the DHS data. Despite that, our study had few important limitations. Due to the nature of data (secondary data), we had no control over confounders and the measurement of indicators. Since DHS data did not have country-level factors we did not consider them in the analysis.

\section{Conclusion}

The study found that comprehensive knowledge about HIV/AIDS in sub-Saharan Africa is low. Factors both at the individual and community level were associated with comprehensive knowledge about HIV/AIDS. Therefore, giving special attention to those young women, women who had no formal education, those from poor socioeconomic status, and those who are from remote areas could decrease the epidemics of HIV/AIDS by increasing the comprehensive knowledge about HIV/AIDS. Besides, it is better to strengthen media campaigns regarding HIV/ AIDS to increase comprehensive knowledge about HIV/ AIDS.

\section{Abbreviations}

AIDS: Acquired immunodeficiency virus; AOR: Adjusted odds ratio; Cl: Confidence interval; HIV: Human immunodeficiency virus; ICC: Intraclass correlation 
coefficient; MOR: Median odds ratio; PCV: Proportionate change in variance; SSA: Sub-Saharan African.

\section{Acknowledgements}

Our deepest gratitude and appreciation go to the measure DHS program for allowing us to use the data set.

\section{Authors' contributions}

ABT, YY, AML, MGW, HGA, ZTT, AZA, GAT, and TSA were involved in the initiation of the research concept, analyzed the data, presented and interpreted the results, and wrote up the draft manuscript. All authors read and approved the final manuscript.

\section{Funding}

No funding.

\section{Availability of data and materials}

All result-based data is in the manuscript and anyone can access the data set from https://dhsprogram.com.

\section{Declarations}

\section{Ethics approval and consent to participate}

This study was conducted under the Declaration of Helsinki and since we were using publicly accessible data, ethical approval was not needed. In addition, this research was considered exempt by the Institute of Public Health, College of Medicine and Health Sciences, University of Gondar Institutional Review Committee. However, by registering or online requesting we have accessed the data set from the DHS website (https://dhsprogram.com).

\section{Consent for publication}

Not applicable.

\section{Competing interests}

The authors declare that they have no competing interests.

\section{Author details}

'Department of Epidemiology and Biostatistics, Institute of Public Health, College of Medicine and Health Sciences, University of Gondar, Gondar, Ethiopia. ${ }^{2}$ Department of Physiology, School of Medicine, College of Medicine and Health Sciences, University of Gondar, Gondar, Ethiopia. ${ }^{3}$ Department of Midwifery, School of Nursing and Midwifery, College of Medicine and Health Sciences, Wollo University, Dessie, Ethiopia. ${ }^{4}$ Department of Human Anatomy, College of Medicine and Health Science, School of Medicine, University of Gondar, Gondar, Ethiopia.

Received: 27 May 2021 Accepted: 2 February 2022

Published online: 07 February 2022

\section{References}

1. World Health organization. Global health sector strategy on HIV, 2016-2021. https://www.who.int/news-room/fact-sheets/detail/hiv-aids.

2. Mahy M, Marsh K, Sabin K, Wanyeki I, Daher J, Ghys PD. HIV estimates through 2018: data for decision-making. AIDS (London, England). 2019;33(Suppl 3):S203.

3. AVERT. GLOBAL HIV AND AIDS STATISTICS. 18 February 2019.

4. HIV/AIDS JUNPO. 2008 report on the global AIDS epidemic: Unaids; 2008.

5. Warren CE, Hopkins J, Narasimhan M, Collins L, Askew I, Mayhew SH. Health systems and the SDGs: lessons from a joint HIV and sexual and reproductive health and rights response. Health Policy Planning. 2017:32(Suppl 4):iv102.

6. Assembly G. Sustainable development goals. SDGs Transform Our World. 2015;2030.

7. Zeng W, Shepard DS, Avila-Figueroa C, Ahn H. Resource needs and gap analysis in achieving universal access to HIV/AIDS services: a data envelopment analysis of 45 countries. Health Policy Plan. 2016;31(5):624-33.
8. McRobie E, Matovu F, Nanyiti A, Nonvignon J, Abankwah DNY, Case KK, et al. National responses to global health targets: exploring policy transfer in the context of the UNAIDS '90-90-90' treatment targets in Ghana and Uganda. Health Policy Plan. 2018;33(1):17-33.

9. World Health Organisation. 10 facts on HIV/AIDS. Available from: https:// www.who.int/features/factfiles/hiv/facts/en/index3.html.

10. Bunyasi EW, Coetzee DJ. Relationship between socioeconomic status and HIV infection: findings from a survey in the Free State and Western Cape Provinces of South Africa. BMJ Open. 2017;7(11):e16232.

11. Gavin L, Galavotti C, Dube H, McNaghten A, Murwirwa M, Khan R, et al. Factors associated with HIV infection in adolescent females in Zimbabwe. J Adolesc Health. 2006;39(4):596.

12. Ang LW, Low C, Wong CS, Boudville IC, Toh MPHS, Archuleta S, et al. Epidemiological factors associated with recent HIV infection among newly-diagnosed cases in Singapore, 2013-2017. BMC Public Health. 2021;21(1):1-12.

13. Pereira Bde S, Costa MC, Amaral MT, da Costa HS, da Silva CA, Sampaio VS. Factors associated with HIV/AIDS infection among adolescents and young adults enrolled in a Counseling and Testing Center in the State of Bahia, Brazil. Ciencia \& Saude Coletiva. 2014;19(3):747-58.

14. Teshome R, Youjie W, Habte E, Kasm N. Comparison and association of comprehensive HIV/AIDS knowledge and attitude towards people living with HIV/AIDS among women aged 15-49 in three east African countries: Burundi, Ethiopia and Kenya. J AIDS Clin Res. 2016;7(4):1-8.

15. Oljira L, Berhane Y, Worku A. Assessment of comprehensive HIV/AIDS knowledge level among in-school adolescents in eastern Ethiopia. J Int AIDS Soc. 2013;16(1):17349.

16. Sohn A, Park S. HIV/AIDS knowledge, stigmatizing attitudes, and related behaviors and factors that affect stigmatizing attitudes against HIV/ AIDS among Korean adolescents. Osong Public Health Res Perspect. 2012;3(1):24-30.

17. Mude W, Oguoma VM, Gesesew HA, Ameyaw EK, Njue C, Nyanhanda T, et al. HIV/AIDS knowledge and attitudes assessment among women of child-bearing age in South Sudan: findings from a Household Survey. PLoS ONE. 2020;15(12):e0243969.

18. Ankunda D, Asiimwe JB. Determinants of comprehensive knowledge of HIV/AIDS among women of the reproductive age (15-49) in Uganda. Int J Community Med Public Health. 2017:4(10):6.

19. Agegnehu CD, Geremew BM, Sisay MM, Muchie KF, Engida ZT, Gudayu TW, et al. Determinants of comprehensive knowledge of HIV/AIDS among reproductive age (15-49 years) women in Ethiopia: further analysis of 2016 Ethiopian demographic and health survey. AIDS Res Ther. 2020;17(1):1-9.

20. Fenny AP, Crentsil AO, Asuman D. Determinants and distribution of comprehensive HIV/AIDS knowledge in Ghana. Glob J Health Sci. 2017:9(12):32.

21. Gebremedhin S, Wang Y, Tesfamariam E. Predictors of HIV/AIDS knowledge and attitude among young women of Nigeria and Democratic Republic of Congo: cross-sectional study. J AIDS Clin Res. 2017;8(3):677.

22. Croft TN, Marshall AM, Allen CK, et al. 2018. Guide to DHS Statistics. Rockville, Maryland, USA: ICF.

23. Ochako R, Ulwodi D, Njagi P, Kimetu S, Onyango A. Trends and determinants of Comprehensive HIV and AIDS knowledge among urban young women in Kenya. AIDS Res Ther. 2011:8:11.

24. Sheikh MT, Uddin MN, Khan JR. A comprehensive analysis of trends and determinants of HIV/AIDS knowledge among the Bangladeshi women based on Bangladesh Demographic and Health Surveys, 2007-2014. Archives of Public Health. 2017;75(1):1-11.

25. Tessema ZT, Teshale AB, Tesema GA, Tamirat KS. Determinants of completing recommended antenatal care utilization in sub-Saharan from 2006 to 2018: evidence from 36 countries using Demographic and Health Surveys. BMC Pregnancy Childbirth. 2021;21(1):1-12.

26. The DHS Program. Sampling and Weighting with DHS Data. Sep 2015. https://blog.dhsprogram.com/sampling-weighting-at-dhs/.

27. Cicciò L, Makumbi M, Sera D. An evaluation study on the relevance and effectiveness of training activities in Northern Uganda. Rural Remote Health. 2010;10(1):51.

28. Hossain M, Mani KK, Sidik SM, Shahar HK, Islam R. Knowledge and awareness about STDs among women in Bangladesh. BMC Public Health. 2014;14(1):1-7. 
29. Kefale B, Damtie Y, Yalew M, Adane B, Arefaynie M. Predictors of comprehensive knowledge of HIV/AIDS among people aged 15-49 years in Ethiopia: a multilevel analysis. HIV/AIDS (Auckland, NZ). 2020;12:449-56.

30. Yaya S, Bishwajit G, Danhoundo G, Shah V, Ekholuenetale M. Trends and determinants of HIV/AIDS knowledge among women in Bangladesh. BMC Public Health. 2016;16(1):1-9.

31. Huy NV, Lee H-Y, Nam Y-S, Tien NV, Huong TTG, Hoat LN. Secular trends in HIV knowledge and attitudes among Vietnamese women based on the Multiple Indicator Cluster Surveys, 2000, 2006, and 2011: what do we know and what should we do to protect them? Glob Health Action. 2016;9(1):29247.

32. Dimbuene ZT, Defo BK. Fostering accurate HIV/AIDS knowledge among unmarried youths in Cameroon: do family environment and peers matter? BMC Public Health. 2011;11(1):1-12.

\section{Publisher's Note}

Springer Nature remains neutral with regard to jurisdictional claims in published maps and institutional affiliations.

- fast, convenient online submission

- thorough peer review by experienced researchers in your field

- rapid publication on acceptance

- support for research data, including large and complex data types

- gold Open Access which fosters wider collaboration and increased citations

- maximum visibility for your research: over 100M website views per year

At BMC, research is always in progress.

Learn more biomedcentral.com/submissions 